УДК 811.161.1

ББК 81.411.2-3

DOI: https://doi.org/10.17308/lic.2020.1/2740

\title{
ПРЕДЛОЖЕНИЯ, ВЫРАЖАЮЩИЕ СИТУАЦИИ ОСЯЗАНИЯ, В РУССКОМ СЕМАНТИКО-ФУНКЦИОНАЛЬНОМ СИНТАКСИСЕ
}

\author{
В. Ю. Копров, А. Л. Лебедева \\ Воронежский государственный университет
}

\section{SENTENCES EXPRESSING SITUATIONS OF TOUCH IN RUSSIAN SEMANTIC-FUNCTIONAL SYNTAX}

\author{
V. Yu. Koprov, A. L. Lebedeva \\ Voronezh State University
}

\begin{abstract}
Аннотация: одной из важнейших проблем функциональной лингвистики является изучение отражения в языке восприятия человеком окружающего мира, в том числе осязательного восприятия. На синтаксическом уровне языка оно реализуется как разновидность субъектно-объектных отношений, выражаемых простыми предложениями. В наших исследованиях при описании семантики и структуры предложения применяется методика поаспектной характеристики его устройства. Важнейшим аспектом является номинативный, в рамках которого выделяются два подаспекта: ситуативно-структурный и релятивно-структурный. Предложения осязания образуют семантико-функциональное поле, имеющее в своей структуре ядро и периферию. В основе семантико-структурной организации предложений данного типа лежит глагол, поэтому выражаемые ими варианты семантической структуры определяются принадлежностью глагола к определенному лексико-грамматическому разряду (ЛГР). Глаголу «касаться» отводится роль базисного идентификатора, поскольку любое осязание начинается с прикосновения к предмету. Кядру поля относятся предложения с глаголами контактно-направленного действия (касаться, трогать, щупать). Периферия поля представлена предложениями с глаголами пяти ЛГР: касания объекта без его перемещения; касания объекта с его перемещением; движения субъекта с семой касания объекта; звучания с семой касания объекта; локализации с семой касания объекта. В инвариантной семантической структуре предложений, выражающих ситуации осязания, выделяются обязательные (субъект и объект) и факультативные (инструмент, локализатор) именные актанты. В качестве факультативного компонента чаще всего выступает инструмент, под которым понимается предмет, вовлеченный в действие и способствующий его осуществлению. Инструмент далее субкатегоризируется на неотчуждаемый и отчуждаемый.

Ключевые слова: семантико-функииональный синтаксис, поаспектная методика анализа устройства предложения, номинативный аспект, семантико-функциональное поле осязания, обязательные и факультативнье актанты ситуации осязания.
\end{abstract}

\begin{abstract}
: one of the main problems of functional linguistics is the scientific study of human perception of the outer world, including tactile (haptic) perception. On the syntactic level of language, it is implemented as a kind of subject-object relations expressed by simple sentences. In our studies we describe semantics and structure of sentences using the aspect-by-aspect techniques. The main aspect is nominative, which in its turn is divided into situational-and-structural and relative-structural. The sentences of touch form a semantic-functional field that has a core and periphery in its structure. The basis of the organization of sentences of this semantic-structural type is a verb, therefore, the variants of the semantic structure are determined by a certain lexical and grammatical category $(L G C)$ of the verb. The verb to touch plays the role of the basic identifier of constructions constituting the studied semantic-functional field, since any touch begins with a physical or mental touch on the subject. To the core of the field belong the sentences with verbs of contact-directed action (to touch). The field periphery is
\end{abstract}

(C) Копров В. Ю., Лебедева А. Л., 2020

Контент доступен под лицензией Creative Commons Attribution 4.0 License.

The content is available under Creative Commons Attribution 4.0 License. 
represented by sentences with verbs of five other LGC: touch of the object without moving it; touch of the object with moving it; subject movement with the seme of touching the object; sound with the seme of touching the object; localization with the seme of touching the object. In the invariant semantic structure of sentences expressing touch situations there are obligatory (subject and object) and optional (instrument, localizer) nominal actants. As an optional actant most often acts an instrument, which is understood as an object involved in the action and contributing to its implementation. The instrument is further subcategorized into an inalienable and an alienable one.

Key words: semantic-functional syntax, aspect-by-aspect analysis techniques, the nominative aspect, semanticfunctional field of touch, obligatory and optional actants.

Использование семантико-функционального подхода в синтаксисе требует создания операционной модели описания предложения, которая давала бы знания о том, какие языковые комплексы обеспечивают тот или иной участок системы языка. В качестве одной из таких моделей предлагается методика поаспектной характеристики устройства и функционирования предложения-высказывания, которая объединяет описание компонентов семи аспектов: целевого, номинативного, предикативного, релятивно-номинативного, актуализирующего, эмоционально-экспрессивного и стилистического [1, с. 61-69].

Важнейшим из них является номинативный аспект, в рамках которого выделяются два подаспекта: ситуативно-структурный и релятивно-структурный. В свете ситуативно-структурного подаспекта строение предложения рассматривается как опосредованное языком отражение структуры предметной ситуации. При этом предложения сначала дифференцируются по семантике и количеству предметных (актантных) и признакового компонентов их семантической структуры, затем - по принадлежности признакового компонента к той или иной части речи, далее - по принадлежности актантов к тому или иному лексико-грамматическому разряду слов (ЛГР) внутри частей речи [1, с. 72-82]. Задачей настоящей статьи является анализ предложений с семантикой осязания в ситуативно-структурном аспекте их организации.

В настоящее время ведущим принципом лингвистический парадигмы является антропоцентризм, в свете которого язык рассматривается в тесной связи с внутренним миром человека. Поскольку человек воспринимает и осознает мир посредством органов чувств и на этой основе создает систему представлений о мире, изучение процессов восприятия и отражения в языке окружающего мира является одной из главных задач семантико-функциональной лингвистики.

К базовым лексическим единицам, обозначающим восприятие, относятся глаголы видеть, cльшать, обонять, ощущцать вкус и осязать, отмечается Е. В. Урысон [2, с. 3-21].

Ситуация восприятия включает двух участников: субъект восприятия и объект восприятия. Само вос- приятие может отражаться как пассивное, когда субъект просто воспринимает какой-нибудь объект, например: Он видел ее каждый день; Я сльшу пение птиц в лесу. Если субъект делает что-то специально, для того чтобы воспринимать объект, восприятие отражается в языке как активное: Он смотрел на нее каждый день; Я слушаю пение птии в лесу. Для каждого вида пассивного восприятия имеется парный глагол, обозначающий активное действие. Ср.: видеть - смотреть, сльишать - слушать, обонять - нюхать, ощущуать вкус - пробовать, осязать - щупать. Язык, глаза, нос, уши - органы восприятия, которые имеют внешний вид и выполняют свои определенные функции. В то же время для осязания используются разные части тела: рука, ладонь, пальцы, губы, нога, кожа. Осязание - сложная ассоциация разнородных ощущений, относящаяся прежде всего к области кожной чувствительности. Оно включает в себя тактильные (прикосновения и давления), температурные (холод и тепло), болевые ощущения и существует только в комплексе [3, с. 15]. Осязание в процессе познания в полной мере используется только человеком, что подтверждает выражение из английского языка human touch, которое имеет два значения: «человеческое прикосновение» и «человеческое измерение».

Активное осязание - это процесс формирования осязательного образа предмета в ходе его ощупывания, при этом одну из ведущих ролей играют кинестетические ощущения. Пассивное осязание - процесс формирования осязательного образа предмета в результате перемещения его по отношению к неподвижной руке или пальцам, при котором одну из ведущих ролей играют тактильные ощущения. Активное осязание изучается гаптикой (от греч. hapto-хватаю, касаюсь).

Как отмечает Г. Е. Крейдлин, касание - это установление физического контакта, это ощущение, напрямую связанное с кожей, самым важным после мозга органом человека. В языке пассивное восприятие выражается глаголом осязать, так как осязать означает воспринимать телом, например: ...И сквозь распадавшуюся летнюю обувь он необыкновенно живо осязал землю... (В. Набоков). Когда же человек совершает рукой активные действия, происходит активное восприятие, выражаемое глаголом щупать. 
Возрастные стадии развития человека определяют, какие органы чувств будут играть приоритетную роль в познании мира. Так, для ребенка важнейшим способом восприятия является осязание. Младенец открывает для себя мир благодаря тактильным ощущениям, трогая все, что попадается ему под руку. Кроме того, визуальное восприятие оказывается недостаточным как для дошкольников, так и для младших школьников, которые при первом знакомстве с предметом стремятся потрогать его руками, переместить. Вообще люди любят трогать все новое и необычное, поэтому в залах музеев, на вернисажах и выставках развешаны таблички: «Руками не трогать!». Существуют общественные группы, и даже народы, которые можно назвать «трогающими». К «трогающим людям» Г. Е. Крейдлин относит врачей, медсестер, парикмахеров, банщиков, массажистов, портных, косметологов [4, с. 412-456].

Обучение чтению слепых базируется на осязании, на восприятии пальцами выпуклого шрифта (шрифта Брайля). Для слепоглухонемых пальпация имеет также большое значение при восприятии речи, поскольку «слушание» речи для них способом «чтения с голоса» состоит в том, что слепоглухонемой прикладывает руку тыльной стороной кисти к шее говорящего в области голосового аппарата и путем тактильно-вибрационного восприятия улавливает речь. Осязание может осуществляться и ногами, например, осязание рельефа почвы через подошвы обуви при ориентировке слепых, протезное осязание. В случае необходимости обследования особо мелких предметов при слепоте используется также ротовое осязание [5].

Первичная ситуация восприятия включает двух основных участников. Первый - тот, кто воспринимает, второй - то, что воспринимается [6, с. 357]; субъектом восприятия выступают одушевленные существа, а объектом - все те реалии, которые могут быть восприняты рецепторами. В свете предлагаемой модели семантико-функционального синтаксиса ситуации осязания находят свое отражение в простых предложениях с типовым значением «субъектно-объектные отношения» и инвариантной семантической структурой «субъект - действие - объект».

В основе организации предложений данного семантико-структурного типа лежит глагол, поэтому выражаемые ими варианты семантической структуры определяются принадлежностью глагола к определенному лексико-грамматическому разряду (ЛГР).

Рассматриваемые предложения составляют семантико-функциональное поле средств выражения осязания. Как во всяком поле, здесь имеется ядро и периферия.

К ядру поля относятся предложения с глаголами контактно-направленного действия: щуnать, касать- ся, трогать. Глаголу касаться отводится роль базисного идентификатора в построении поля осязания, поскольку любое осязание начинается с физического или ментального прикосновения к предмету.

Определяя значение глагола осязать, «Малый академический словарь» возводит его к значению существительного осязание. Получается, что ощущение, которое это существительное обозначает, первичнее, чем процесс, обозначаемый глаголом: осязать 1. Воспринимать путем осязания. 2. перен. Ощущать, воспринимать, замечать [7, т. 2, с. 660-661].

Осязание - ощущение, полученное от прикосновения или касания рукой, кожей, оно является не процессом, а результатом действия касания. В «Большом толковом словаре русских глаголов» под редакцией Л. Г. Бабенко дается следующее определение глагола осязать: перен. Воспринимать что-либо, ощущая, замечая внутренними чувствами, словно соприкасаясь кожей с чем-либо, распознавая ощупью [8, с. 246].

Глагол осязать тяготеет к развитию отвлеченных значений, связанных с общим восприятием - осмыслением мира: Все жаждали очами осязать Сей чудный образ, созданнылй искусством (А. Одоевский); Руки несытые я простираю, Чтобы весь мир осязать! (В. Брюсов); ...его служитель через мыиление подлинно осязал этот мир в его непосредственности (С. Булгаков).

Рассмотрим представленные в «Малом академическом словаре» значения глагола щупать.

1. Трогать рукой, пальцами и т. п. Щупать пульс. Материю [Варенька] щупала, смотрела на свет и нюхала, примеряла, завернувиись в нее перед зеркалом (Сергеев-Ценский, Недра). 2. Исследовать щупом (...). Саперы деловито щупали металлоискателем улицы, дома (Галин, Годы нашей жизни). 3. Перен. разг. Осторожно расспрашивать, выведывать, стараясь выяснить что-л., составить мнение и т. П. Берсенев заметил, что посреди всех своих проказ, выходок и шуток Шубин все как будто бы экзаменовал Инсарова, как будто щупал его (Тургенев, Накануне) [8, т. 4, с. 744].

О. Ю. Авдевниной отмечается, что все три значения глагола щулать содержат семантику цели. Глагол щупать называет действие, осуществляемое с конкретной, чаще всего узко практической целью - обследовать объект, определить качество предмета [9, c. 261-277].

К периферии поля относятся предложения с глаголами следующих ЛГР.

1. ЛГР глаголов касания объекта без его перемещения.

1.1. ЛГР касания объекта без его перемещения и изменения (касаться, трогать, щулать и т. д.): Белье кудри чесала Дедушке Сашина мать, Гладила их, 
целовала, Сашу звала целовать. Правой рукою мамашу Дед обхватил, а другой Гладил румяного Сашу... (Н. Некрасов); Но вот кончается дорога дальняя, Земли касается звезда кристальная (К. Бальмонт); Рыжеволосый внучонок щупает в книжке листы (С. Есенин).

1.2. ЛГР касания объекта без его перемещения, но с изменением.

1.2.1. Подгруппа глаголов созидания объекта (в результате физического труда) (вязать, клеить, лепить и т. д.): Слушать песни подруг светлооких, И по бархату золотом шить (И. Никитин); Рука фигурки лепит И учит бытию (Г. Иванов); Он вяэет нить изитат и ссылок метафизическим узлом (В. Меркурьева).

1.2.2. Подгруппа глаголов разрушения, повреждения поверхности объекта или тела живого существа (грызть, колоть, кусать, крошить, рвать и т. д.): Твои обвиненья мне сердие грызут (М. Цветаева); Он очень долго смотрит на деревья и очень долго мел крошит в руке. (Е. Евтушенко).

2. ЛГР касания объекта с его перемещением (толкать, прислонять): Пьишут пенковые трубки, Сдвинули чепщы соседки (М. Цветаева); Худой конторщик с головою Листа к колонне прислоняется щзекой (С. Чёрный).

3. ЛГР движения субъекта с семой касания объекта (задеть, наехать): Иду я разросшимся садом, Лицуо задевает сирень (С. Есенин); Опять на сердиуе легче станет, Нахлынет счастие - волнами (М. Цветаева).

4. ЛГР звучания с семой касания объекта (чокаться, чиркать): Слова не одни ли и те же В окошко стучат как дожди (Л. Мартынов); Стучит башкой об стол, заснув, заочник (И. Бродский); И карандашиками чиркают по карте Названия особо пьинных мест (С. Чёрный).

5. ЛГР локализации с семой касания объекта (пересекать, лепиться): Там, над ручьем, сплеталась с веткой ветка (Б. Ахмадулина); ...ладонь с ладонью - Так наша жизнь слилась с гармонью (М. Цветаева); Дороги и пути скрещцивются, путаются, переплетаются (И. Аксенов).

Ситуации касания прослеживаются в многочисленных отраженных сознанием ситуациях объективного мира, следовательно, сочетаемость глаголов рассматриваемой группы весьма широка, и в позиции именных актантов в предложениях функционируют существительные разной семантики.

Например: Твоя рука тиха, легка, Когда касается виска... (О. Мандельштам); И чьи-то волосы напудренные Моих касаются волос... (Г. Иванов); Ни стоном, ни взглядом Окаянной души не коснусь... (А. Ахматова).
В инвариантной семантической структуре предложений, выражающих ситуацию касания, выделяются обязательные и факультативные именные актанты.

Обязательные актанты входят в состав лексико-грамматических вариантов семантических структур всех предложений, а факультативные - только в состав предложений с глаголами определенных ЛГР. Достаточно выделить несколько типов потенциального лексического наполнения обязательных актантных позиций - субъекта:

1) абстрактный субъект: И прелесть улочек портовых Вновь за душу меня берет (Ю. Друнина);

2) субъект-антропоним: Мама взволнованно к сердиу прижала Маленький томик (М. Цветаева);

3) субъект-зооним: Я возвращаюсь. Лижет мне ладони Пушистый кот, мурлькает умильней... (А. Ахматова);

4) неодушевленный субъект: Вот я стою ни женщзина, ни девочка, и ветер меня гладит по плечам (Б. Ахмадулина);

и объекта:

1) абстрактный объект: Смотри, всё ближе с двух сторон Нас обнимает лес дремучий (А. Толстой);

2) одушевленный объект: Иматери каждой, что гладит ребенка, Мне хочется крикнуть: «Весь мир у тебя!» (М. Цветаева);

3) неодушевленный объект: Прижимаю к сердиу крестик гладкий: Боже, мир душе моей верни (А. Ахматова).

В предложениях с глаголами касания различных ЛГР наблюдаются следующие факультативные актанты.

1. ЛГР глаголов касания объекта без его перемещения.

1.1. В предложениях с глаголами касания без его перемещения и изменения в качестве факультативного актанта чаще всего выступает абстрактное понятие или инструмент, под которым понимается предмет, вовлеченный в действие и способствующий его осуществлению. Инструмент часто субкатегоризируют на неотчуждаемый (часть тела рука, палец, нога и т. п.) и отчуждаемый (нож, молоток, лопата и т. п.): Иприжмусь расстрелянным, жалким телом К испуганной, смятой траве. И в мечте прикоснусь губами несмело $К$ русой твоей голове (А. Баркова); Средь суеть, в плену успеха, вдруг, Тебя безжалостно за горло схватит Холодныли ручищами испуг... (Ю. Друнина); Если я к руке опущченной Ртом прильну - не вздумай хмуриться! (М. Цветаева).

1.2. В предложениях с глаголами касания без перемещения объекта, но с его изменением в качестве факультативного актанта также регулярно выступает 
инструмент: $A$ mот, кто - по Цельсию спит - в тепле, ...nинает носком покрывало звезд (И. Бродский); Дождь изарапал льдинками виски (Р. Рождественский); Корвет разрезает волны профилем Франияа Листа (И. Бродский).

2. В предложениях с глаголами ЛГР касания объекта с его перемещением в качестве факультативного актанта регулярно выступает локализатор - актант, указывающий на местоположение объекта: Конечно, когда наработаешься, наломаешься или набегаешься за день, то, чтобы заснуть, достаточно прислонить головук подушке (А. Рыбаков); Министр приставил к глазу свой лорнет (А. Толстой).

3. В предложениях с глаголами ЛГР движения субъекта с касанием объекта в качестве факультативного актанта может выступать инструмент: Утро встречает прохладой рабочих... (О. Берггольц); Споткнулся колесами о выбоины мостовой (М. Зенкевич).

4. В предложениях с глаголами ЛГР звучания с касанием в качестве факультативных актантов чаще всего выступает инструмент: Глупонов тут явился, Надутый, как павлин, с пустою головой, Глядится в зеркало и шаркает ногой (К. Батюшков); Tыл стукнул молотком по шляпке ржавой (3. Гиппиус).

5. В предложениях с глаголами ЛГР локализации с семой касания, в которых локализатор является одновременно и объектом касания, в качестве факультативного компонента может выступать инструмент (чаще всего это часть целого): Путь ветру лбом пересекает (Д. Хармс); Но тайный рок соединяет Teперь нас общею враждой (А. Пушкин).

Таким образом, в свете ситуативно-структурного подаспекта строение предложений с семантикой осязания представляет собой опосредованное языком отражение структуры предметной ситуации осязания. Семантико-функциональное поле осязания структурировано на ядро и периферию. Конституенты поля классифицированы по семантике признакового компонента и по семантике и количеству предметных (актантных) компонентов в их семантической структуре. Предложения дифференцируются также по принадлежности признакового компонента к тому или иному лексико-грамматическому разряду глаголов и принадлежности актантов к определенному лексико-грамматическому разряду существительных.

Дальнейшее изучение предложений, выражающих ситуации осязания, в релятивно-структурном подаспекте номинативного аспекта, а также в других аспектах их устройства и функционирования представляет интерес как для разработки теории семантико-функционального синтаксиса русского языка, так и для практики его преподавания как иностранного.

\section{ЛИТЕРАТУРА}

1. Копров В. Ю. Номинативный аспект структурносемантического устройства простого предложения (на материале русского, английского и венгерского языков) : дис. ... д-ра филол. наук. Воронеж, 1999. 284 с.

2. Урысон E. В. Языковая картина мира VS обиходные представления (модель восприятия в русском языке) // Вопросы языкознания. 1998. № 2. С. 3-21.

3. Ананьев Б. Г., Веккер Л. М., Ломов Б. Ф. Осязание в процессах познания и труда / под ред. Б. Г. Ананьева. М. : Изд-во акад. пед. наук, 1959. 263 с.

4. Крейдлин Г. Е. Невербальная семиотика : Язык тела и естественный язык. М. : Новое литературное обозрение, 2004. 581 с.

5. Рубинштейн С. Л. Основы общей психологии. СПб. : Питер, 2000. 685 с.

6. Апресян Ю. Д. Избранные труды. Т. ІІ. Интегральное описание языка и системная лексикография. М. : Языки русской культуры, 1995. 767 с.

7. Словарь русского языка : в 4 т. / АН СССР, Ин-т рус. яз. ; под ред. А. П. Евгеньевой. 2-е изд., испр. и доп. M. : Русский язык, 1981-1984. T. II. 736 с. ; T. IV. 791 с.

8. Большой толковый словарь русских глаголов. Идеографическое описание. Синонимы. Антонимы. Английские эквиваленты / под ред. Л. Г. Бабенко. М. : АСТ-ПРЕСС КНИГА. 576 с.

9. Авдевнина О. Ю. Категория восприятия и средства ее выражения в современном русском языке : дис. ... Д-ра филол. наук. М., 2014. 384 с.

\section{REFERENCES}

1. Koprov V. Y. Nominativny j aspekt strukturno-semanticheskogo ustrojstva prostogo predlozheniya (na materiale russkogo, anglijskogo $i$ vengerskogo yazy kov) [Nominative aspect of structural-semantic organization of simple sentence (on material of Russian, English and Hungarian languages)]: dis. ... dok. filol. nauk: 10.02.19. Voronezh, 1999. $284 \mathrm{p}$.

2. Uryson E. V. Yazy`kovaya kartina mira VS obixodny`e predstavleniya (model' vospriyatiya $v$ russkom yazy`ke) [The language worldview VS. everyday representations (perception model in Russian)] // Voprosy`yazy`koznaniya. 1998. № 2. Pp. 3-21.

3. Anan'ev B. G., Vekker L. M., Lomov B. F. Osyazanie $v$ processax poznaniya i truda [Touch in the processes of cognition and labor]. Moscow: Izd-vo akad. ped. nauk, 1959. $263 \mathrm{p}$.

4. Krejdlin G. E. Neverbal'naya semiotika: Yazyk tela i estestvennyj yazyk [Nonverbal Semiotics: Body Language and Natural Language]. Moscow: Novoe literaturnoe obozrenie, 2004. 581 p.

5. Rubinshtejn S. L. Osnovy obshhej psikhologii [Fundamentals of General Psychology]. Saint-Petersburg: Izdatel`stvo «Piter», 2000. $685 \mathrm{p}$.

6. Apresyan Y. D. Izbranny'e trudy`: T. II. Integral noe opisanie yazy 'ka i sistemnaya leksikografiya [Selected Works: T. II. Integral language description and systemic 
lexicography]. Moscow: Shkola «Yazyki russkoj kul'tury». 1995. $767 \mathrm{p}$.

7. Slovar 'russkogo yazy 'ka: V 4 t. / AN SSSR, In-t rus. yaz.; pod red. A. P. Evgen'evoj [Dictionary of the Russian language]. 2-e izd., ispr. i dop. Moscow: Russkij yazyk, 1981-1984. T. II. 736 p. ; T. IV. 791 p.

8. Bol shoj tolkovyj slovar' russkix glagolov. Ideograficheskoe opisanie. Sinonimy. Antonimy. Anglijskie ekvivalenty [Large explanatory dictionary of Russian

Воронежский государственный университет

Копров В. Ю., доктор филологических наук, профессор, заведуюший кафедрой русского языка для иностранных учашихся основных факультетов

E-mail:koprov@mail.ru

Лебедева А. Л., кандидат филологических наук, доиент кафедры русского языка для иностранных учащцихся основных факультетов

E-mail:volova25@rambler.ru

Поступила в редакцию 4 октября 2019 г.

Принята к публикаичии 27 декабря 2019 г.

\section{Для циттирования:}

Копров В. Ю., Лебедева А. Л. Предложения, выражающие ситуации осязания, в русском семантико-функциональном синтаксисе // Вестник Воронежского государственного университета. Серия: Лингвистика и межкультурная коммуникация. 2020. № 1. С. 120-125. DOI: https://doi.org/10.17308/lic.2020.1/2740 verbs. Ideographic description. Synonyms Antonyms. English equivalents] / pod redakciej prof. L. G. Babenko. - Moscow: AST-PRESS KNIGA. 576 p.

9. Avdevnina O. Yu. Kategoriya vospriyatiya i sredstva ee vy`razheniya v sovremennom russkom yazy 'ke: dis. ... d-ra filol. nauk: 10.02.01 Category of perception and means of expression in modern Russian: dis. ... dok. filol. nauk: 10.02.01. Moscow, 2014. 384 p.

Voronezh State University

Koprov V. Yu., Doctor of Philology, Professor, Head of the Russian Language for International Students of Main Faculties Department

E-mail:koprov@mail.ru

Lebedeva A. L., Candidate of Philology, Associate Professor of the Russian Language for International Students of Main Faculties Department

E-mail:volova25@rambler.ru

Received: 4 October 2019

Accepted: 27 December 2019

\section{For citation:}

Koprov V. Y., Lebedeva A. L. Sentences expressing situations of touch in Russian semantic-functional syntax. Proceedings of Voronezh State University. Series: Linguistics and Intercultural Communication. 2020. No. 1. Pp. 120-125. DOI: https://doi.org/10.17308/lic.2020.1/2740 